\title{
Hydrogen Exchange Rates of the DNA Oligomer Duplex, d[CGCGCGCCATAAC]/ d[GTTATGGCGCGCG] Determined by NMR Spectroscopy
}

\author{
Jongchul Bang, ${ }^{\dagger}$ Young-Min Kang, Byong-Seok Choi, ${ }^{\dagger+*}$ and Joon-Hwa Lee \\ Department of Chemistry and Research Institute of Natural Science and Research Institute of Life Science, \\ Gyeongsang National University, Jinju, Gyeongnam 660-701, Korea. E-mail: joonhwa@gnuackr \\ "Department of Chemistry, National Creative Initiative Center, Korea Advanced Institute of Science and Technolog, \\ Daejeon 305-701, Korea. "E-mail: byongseokchoi@kaistackr \\ Received September 30, 2007
}

Key Words : NMR, IIydrogen exchange, Imino proton, Base pair stability, B-Z junction

The measurement of hydrogen exchange rates has been an important tool for studying the macromolecular conformation or dynamics. ${ }^{2}$ The imino proton resonances of nucleic acids are good probes of the hydrogen exchange study for studying the dynamics of each base pair. ${ }^{1,2}$ The exchange rates of imino protons depend on not only the base pair stability but also solvent accessibility. ${ }^{2}$ Hydrogendeuterium (H/D) exchange method is widely used to measure the exchange rates of slowly exchanging imino protons, whereas the exchange rates of fast-exchanging imino protons can be determined by water magnetization transfer method of NMR. ${ }^{1,2}$

NMR hydrogen exchange experiment can provide the information on the thermodynamics and kinetics for basepair opening in the nucleic acids. ${ }^{2}$ Lots of results of these experiments determined in various DNAs, ${ }^{3-6} \mathrm{RNAs}^{6,7}$ and DNA-protein complexes ${ }^{89}$ were reported. Analysis of the hydrogen exchange of imino protons generally was based in the two-state (open/closed) model for the base pair where hydrogen exchange only occurs from the open state. ${ }^{12,10}$ The opening/closing rate constants and/or equilibrium constant for base-pair opening can often be detemined by measuring the exchange as a function of the concentration of extemal catalysts such as ammonia or TRIS.

Left-handed Z-DNA is a higher-energy form of the double helix produced at an altemating $\mathrm{CG}$ sequence region and is stabilized by high salt concentration or negative super-coiling. ${ }^{11}$ Recently, X-ray crystal structure of the B-Z junction induced by the Z-DNA binding protein, where the altemating CGCGCG exhibited left-handed Z-DNA whereas a nonaltemating AT-rich region maintained B-form helix, was reported. ${ }^{12}$ They also found the continuous stacking of bases between B-DNA and Z-DNA segments with the breaking of one base pair at the junction. ${ }^{12}$ This result indicates that the one base pair at the B-Z junction should be destabilized and then its bases might be extruded to allow the $\mathrm{B}-\mathrm{Z}$ conformational change at the CGCGCG region. Here, we measured the imino proton exchange rates for a bzDNA-13 DNA duplex formed by an 15-nt bzA-15mer, d[GTCGCGCGCCATAAC] and a 13-nt bzB-13mer, d[GTTATGGCGCGCG] (Fig. 1A) by water magnetization transfer method to understand the dynamic character of base pairs.

\section{Experimental Section}

DNA oligonucleotides, bzA-15mer and bzB-13mer (Figure 1A) were obtained from Genotech (Daejeon, Korea). Each oligonucleotide was purified and desalted by Sephadex G-25 column. DNA duplex, bzDNA-13, was prepared by dissolving the bzA-15mer and bzB-13mer strands at a 1:1 stoichiometric ratio in an NMR buffer $(10 \mathrm{mM}$ sodium phosphate $(\mathrm{pH} 8.0), 100 \mathrm{mM} \mathrm{NaCl}$ in $90 \% \mathrm{H}_{2} \mathrm{O} / 10 \% \mathrm{D}_{2} \mathrm{O}$ ). NMR experiments were carried out on a Varian Inova $600-\mathrm{MHz}$ spectrometer (KAIST, Daejeon) equipped with $\mathrm{x}, \mathrm{y}, \mathrm{z}$-axis pulsed-field gradient triple resonance probe. ID NMR data were processed and analyzed with the program FELIX (Accelrys) or VNMR J as previously described. ${ }^{13}$ 2D NMR data were processed with the program NMRPIPE and analyzed with the program Sparky as previously described. ${ }^{13.14}$ The exchange rates of the imino protons were determined as previously described. ${ }^{15}$ The apparent longitudinal relaxation rate constants, $R_{t c t}$, of the imino protons were determined by semi-selective inversion recovery $1 \mathrm{D}$ NMR experiments. $^{15}$ The hydrogen exchange rates of the imino protons were measured by water magnetization transfer experiments. ${ }^{15}$ The $R_{f w}$ was determined by water selective inversion recovery experiment. ${ }^{15}$

The imino hydrogen exchange rate constants $\left(k_{e x}\right)$ were determined by fitting the data to $\mathrm{Eq}$. (1):

$$
\frac{I_{o}-I(t)}{I_{0}}=2 \frac{k_{e x}}{\left(R_{1 w}-R_{1 a}\right)}\left(e^{-R_{1 a^{t}}}-e^{-R_{1 w^{t}}}\right)
$$

where $R_{I a}$ and $R_{I w}$ were the independently measured and are the apparent longitudinal relaxation rates of the imino proton and water, respectively, and $I_{0}$ and $I(t)$ are the peak intensities of the imino proton in the water magnetization transfer experiments at times zero and $t$, respectively. ${ }^{10}$

\section{Results and Discussion}

All imino proton resonances from Watson-Crick base pairs of bzDNA- 13 were assigned by the strong G-imino to C-amino or T-imino to A-H2 NOE cross peaks in the watergate NOESY (mixing time: $200 \mathrm{~ms}$ ) acquired at 15 and 35 ${ }^{\circ} \mathrm{C}$. Figure $1 \mathrm{~B}$ shows the temperature dependence of the 
(A)

$$
\text { bzA-15mer }
$$

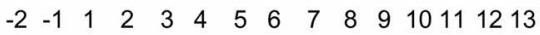

5' -G T C G C G C G C C A T A A C -3'

. . : . . . . .

3'- G C G C G C G G T A T T G -5

26252423222120191817161514

bzB-13mer

(B)

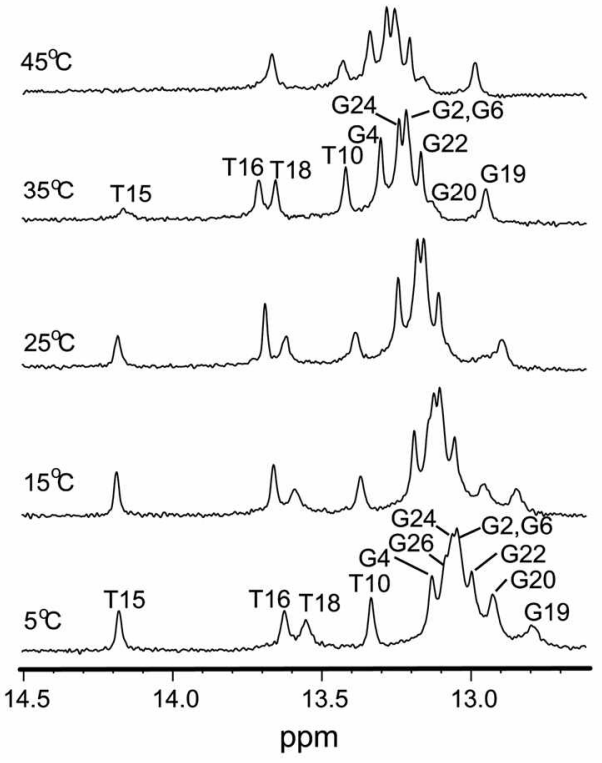

Figure 1. $(\Lambda)$ DNA sequence context of the bZDN $\Lambda-13$ duplex. (B) Temperature dependence of the imino proton resonances of the 'H-NMR spectra for the bzDNA-13 duplex in a NMR buffer containing $10 \mathrm{mM}$ sodium phosphate $(\mathrm{pH} 8.0$ ) and $100 \mathrm{mM} \mathrm{NaCl}$. The experimental temperatures are shown on the left.

(A)

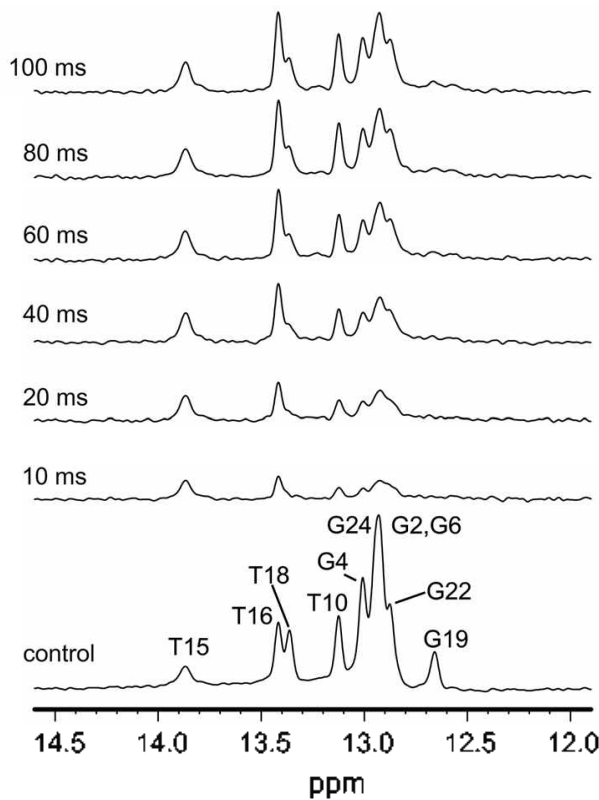

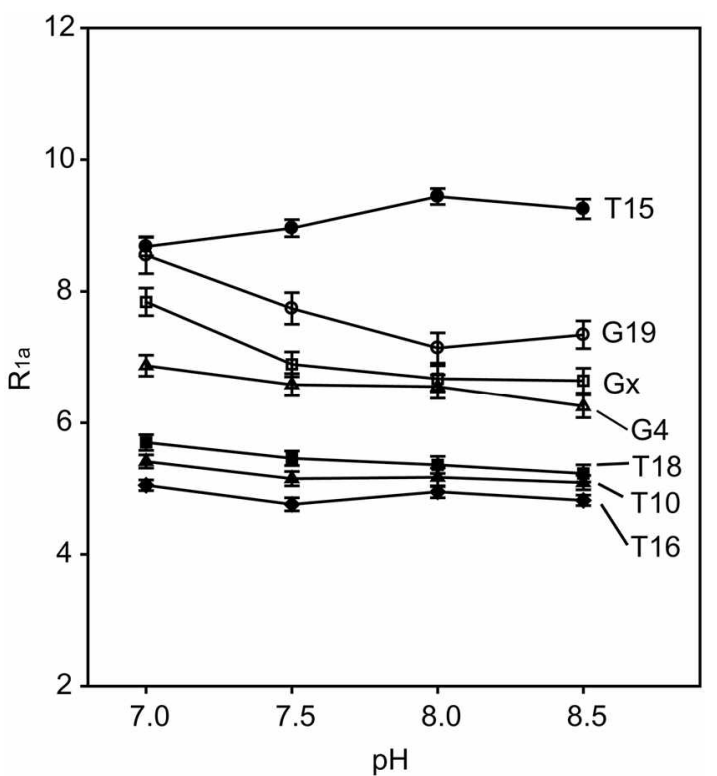

Figure 2. The apparent relaxation rate constants (R1a) (s-1) of the imino proton resonances for the bzDNA-13 duplex as function of $\mathrm{pH}$ of the NMR buffer. The $\mathrm{pH}$ of all NMR buffer containing 10 $\mathrm{mM}$ sodium phosphate, $100 \mathrm{mM} \mathrm{NaCl}$ is adjusted by addition of $\mathrm{NaOH}$ or $\mathrm{HCl}$.

imino proton spectra of the bzDNA-13. All imino proton resonances except the terminal G14 and G26 are still observed up to $35^{\circ} \mathrm{C}$ (Fig. IB). The T15 imino proton resonance became broadened as temperature was increased and then was disappeared at $45^{\circ} \mathrm{C}$, indicating instability of the A12 T15 base pair (Fig. 1B). Although the T18 imino proton resonance showed significant line-broadening at low temperature, it became sharpened at $35^{\circ} \mathrm{C}$ (Fig. IB). Unusually, the $\mathrm{G} 20$ imino proton from central $\mathrm{G}-\mathrm{C}$ base pair

(B)

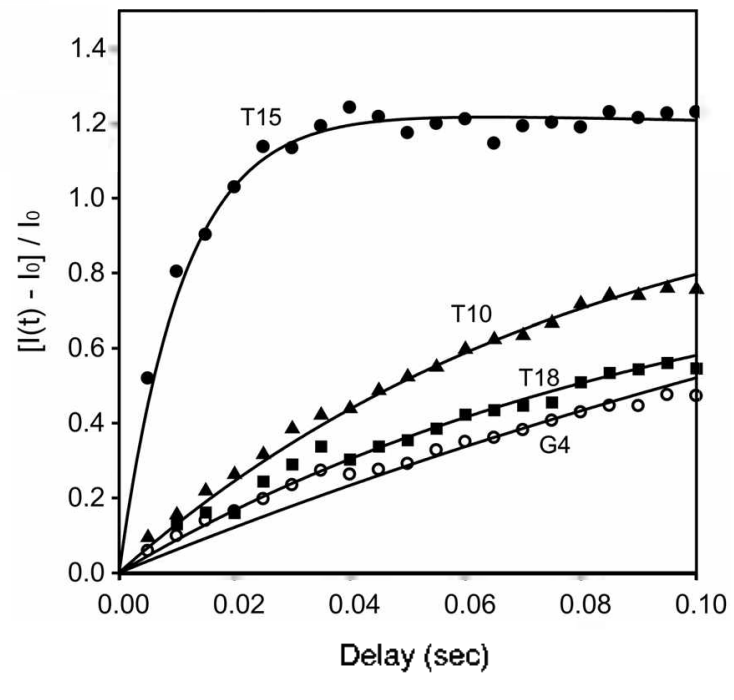

Figure 3. $(\Lambda)$ Difference spectra between the control (no selective inversion for water) and exchange after selective inversion in the water magnetization transfer experiment of imino protons of the bzDNA-13 in an NMR buffer at $35^{\circ} \mathrm{C}$. The delay times after selective water inversion were shown on the left of each spectrum. (B) Relative peak intensities, $\left[(i)-\mathrm{I}_{3}\right] / \mathrm{h}_{\mathrm{h}}$ in the difference spectra for some imino protons as finction of delay time. Solid lines indicate the best fitting of these data using Eq. (1). 
had broadened resonance at high temperature compared to other $G$ imino proton resonances. These results may demonstrate that the unusually unstable conformation is formed between the $\mathrm{CG}$ alternating region and $\mathrm{AT}$ rich region.

The apparent relaxation rate constants, $R_{t \alpha}$, of the imino protons of bzDNA- 13 were determined at $15^{\circ} \mathrm{C}$ as function of $\mathrm{pH}$ (Fig. 2). The $R_{f o}$ of the imino proton is actually the sum of the spin lattice relaxation rate constant $R_{I}$ and $k_{e x .}{ }^{2}$ The $R_{l o}$ for each imino proton was determined by curve fitting of the data from the semi-selective inversion recovery experiments on the imino protons to a single exponential function. ${ }^{15}$ All imino protons showed no or little change of $R_{d a}$ as the $\mathrm{pH}$ varied in the range of $7.5-8.5$ (Fig. 2), indicating that the conformational or dynamics changes of the bzDNA-13 did not occurred in this $\mathrm{pH}$ range. As the $\mathrm{pH}$ increased from 7.5 to 8.5 , the concentrations of two base catalysts, $\mathrm{OH}^{-}$and $\mathrm{HPO}_{4}{ }^{2-}$ are changed $0.32-$ to-3.2 $\mu \mathrm{M}$ and 6.7-to-9.5 mM, respectively. These results mean that the change of the base catalyst concentrations had little effect on the hydrogen exchange of imino protons under this experimental condition.

The exchange rates of the imino protons for the bzDNA13 were determined by water magnetization transfer method at $15^{\circ} \mathrm{C}$ and $35^{\circ} \mathrm{C}$. Figure $3 \mathrm{~A}$ shows $1 \mathrm{D}$ difference spectra on bzDNA- 13 at $35^{\circ} \mathrm{C}$ for the water magnetization transfer experiments as a function of delay time between the selective water inversion and detection pulses. The relative peak intensities of the difference spectra for the imino proton resonances of the bzDNA-13 at $35^{\circ} \mathrm{C}$ are plotted as a function of delay time in Figure 3B. The $k_{e x}$ values of the imino protons were determined by the curve fitting of the data in Figure 3B to Eq. (1). The $k_{e x}$ values for the bzDNA13 at 15 and $35^{\circ} \mathrm{C}$ are given in Table 1 . At $15^{\circ} \mathrm{C}$, most imino protons had the $k_{e x}$ in the range of $1-1.6 \mathrm{~s}^{-1}$, whereas the $\mathrm{G} 20$ and $\mathrm{T} 15$ imino protons were rapidly exchanged $\left(k_{e x:} \geq 3 \mathrm{~s}^{-1}\right)$. However, the significant difference was observed in the $k_{e x}$ of the imino protons of the bzDNA-13 determined at $35^{\circ} \mathrm{C}$. The $\mathrm{G}$ imino protons except $\mathrm{G} 20$ and teminal $\mathrm{G}$ imino

Table 1. Exchange rates $\left(s^{-1}\right)$ of the imino protons for bzDNA-13 in $90 \% \mathrm{H}_{2} \mathrm{O} / 10 \% \mathrm{D}_{2} \mathrm{O}$ NMR buffer containing $10 \mathrm{mM}$ sodium phosphate $(\mathrm{pH} 8.0), 100 \mathrm{mM} \mathrm{NaCl}$ at 15 and $35^{\circ} \mathrm{C}$ determined by water magnetization transfer method

\begin{tabular}{cccc}
\hline Base pair & Imino proton & $15^{\circ} \mathrm{C}$ & $35^{\circ} \mathrm{C}$ \\
\hline $\mathrm{G} 2 \cdot \mathrm{C} 25$ & $\mathrm{G} 2$ & & \\
$\mathrm{C} 3 \cdot \mathrm{G} 24$ & $\mathrm{G} 24$ \\
$\mathrm{C} 5 \cdot \mathrm{G} 22$ & $\mathrm{G} 22$ \\
$\mathrm{G} 6 \cdot \mathrm{C} 21$ & $\mathrm{G} 6$ & $1.6 \pm 0.5^{\circ}$ & $3.3 \pm 0.6^{\circ}$ \\
$\mathrm{G} 4 \cdot \mathrm{C} 23$ & $\mathrm{G} 4$ & & \\
$\mathrm{C} 7 \cdot \mathrm{G} 20$ & $\mathrm{G} 20$ & $3.4 \pm 0.5$ & $3.2 \pm 0.7$ \\
$\mathrm{C} 8 \cdot \mathrm{G} 19$ & $\mathrm{G} 19$ & $1.0 \pm 0.9$ & $3.5 \pm 1.4$ \\
$\mathrm{~A} 9 \cdot \mathrm{T} 18$ & $\mathrm{~T} 18$ & $1.2 \pm 0.7$ & $4.6 \pm 0.7$ \\
$\mathrm{~T} 10 \cdot \mathrm{A} 17$ & $\mathrm{~T} 10$ & $1.2 \pm 0.5$ & $6.9 \pm 0.5$ \\
$\mathrm{~A} 11 \cdot \mathrm{T} 16$ & $\mathrm{~T} 16$ & $1.2 \pm 0.6$ & $15.3 \pm 1.2$ \\
$\mathrm{~A} 12 \cdot \mathrm{T} 15$ & $\mathrm{~T} 15$ & $4.9 \pm 0.4$ & $56.0 \pm 3.0$ \\
\hline
\end{tabular}

"These four imino proton resonances were overlapped, "Not determined. protons had smaller $k_{e x:}$ than the $\mathrm{T}$ imino protons, indicating a higher stability for the $\mathrm{G} \cdot \mathrm{C}$ base pairs. In the crystal structure of the complex of the Z-DNA binding protein with the $B-Z$ junction, one $A \cdot T$ base pair was very unstable and thus both bases were flipped out. ${ }^{12}$ Surprisingly, the T18 from the identical A.T base pair with above has the slowest exchanging imino proton with a factor of 2-14 smaller $k_{e x}$ value than the other $\mathrm{T}$ imino protons. This means that this A9.T1 8 base pair is the most stable in the A.T base pair located at AT-rich region contrast to the complex with ZDNA binding protein. The G20 imino proton from the $\mathrm{C} 8 . \mathrm{G} 20$ base pair, which is located between CGCGCG alternating sequence and AT-rich region (see Fig. 1), showed very broadened peak at high temperature (Fig. 1B) and also had a larger $k_{e x}$ than other $\mathrm{G}$ imino protons at $15^{\circ} \mathrm{C}$ (Table 1). This result indicates the instability of the $\mathrm{C} 8 \cdot \mathrm{G} 20$ base pair which may allow the B-Z conformational change of the CGCGCG sequence by binding to protein with maintaining the B-form helix of the AT-rich region. However, the $\mathrm{C} 8$. $\mathrm{G} 20$ base pair might become stable after binding to proteins. Instead, two bases of the A9.T18 base pair were flipped out and then this unusual structure may allow forming the B-Z junction.

Acknowledgements. J.B. and Y.-M.K. were supported by the BK21 project. This work was supported by the Korea Science and Engineering Foundation Grant funded by the Korea Government (MOST) (R01-2007-000-10691-0) to J.H.L. This work was supported by the Korea Research Foundation Grant funded by the Korea Government (MOEHRD, Basic Research Promotion Fund) (KRF-2006331-C00188) to J.-H.L. This Work was supported by the National Creative Research Initiative Program to B.-S.C. from Korea Government (MOST).

\section{References}

I. Leroy, J. L.; Bolo, N.; Figueroa, N.; Plateau, P.; Guéron, M. $J$. Biontol. Strtict. Dhn 1985, 2, 915-939.

2. Guéron, M.; Leroy, J. L. In Methods Enzyntol; James, T. L., Ed.; 1995; Vol. 261. pp 383-413.

3. Snoussi, K.; Leroy, J.-L. Biochemistry 2002, 41, 12467-12474.

4. Folta-Stogniew, E.; Russu, I. M. Biochemistry 1996, 35, 84398449.

5. Wänmläander, S.; Sen, A.; Leịion, M. Biachenistry 2000, $607-$ 615 .

6. Varnai. P.: Canalia, M.; Leroy, J.-L. J. Ant. Cheni. Soc. 2004. 126. $14659-14667$.

7. Nonin, S.; Jiang, F.; Patel, D. J. J. Mol. Biol. 1997, 268, 359-374.

8. Dhavan, G M.; Lapham, J.; Yang, S.; Crothers, D. M. J. Mol. Biol. 1999. 288, 659-671.

9. Cao, C.; Jiang, Y. L.; Stivers, J.; Song, F. Nat. Strtit. Mol. Biol. 2004. $/ 1,1230-1236$.

10. Snoussi, K.; Leroy, J.-L. Biochemistry 2001, 40, 8898-8904.

11. Rich, A.; Timeline, S. Nat. Rev: Genet, 2003, 4, 566-572.

12. Ha, S. C.; Lowenhaupt, K.; Rich, A.; Kim, Y.-G; Kim, K. K. Nattre 2005, 437, $1183-1186$.

13. Lee, J.-H.; Park, C.-J.; Choi, B.-S. Bthl. Korean Chem. Soc. 2006, $27.1731-1732$

14. Lee, J.-H. Bull. Korean Chem. Soc, 2007, 28, 1643-1644.

15. Lee, J.-H.; Pardi, A. Nucleic Acids Res. 2007, 35, 2965-2974. 